\title{
The clinical team: ideology, power, boundaries and the patient
}

\author{
Chris Green, Consultant Forensic Psychiatrist, Stockton Hall Hospital, \\ Stockton-on-the-Forest, York YO3 9UN
}

Over the last 20 to 30 years, the team, multidisciplinary, approach to psychiatry has become firmly established. Proponents would argue that it is essential that a patient has the benefit of the different knowledge bases, skills and approaches, which come from the various professionals forming the clinical team. Using the common Gestalt concept, one might hope that a well-functioning team would exceed in its therapeutic effectiveness the sum total of the skills of its individual members. Such a team should be able to communicate well, draw freely from particular skills of members and be able to adopt a consistent approach in its relationships and interventions with patients. This, however, is not always the case. In my experience, it is not uncommon for clinical teams to suffer from unresolved conflicts between their members. Such conflicts can diminish the team's overall potential and make difficulties in adopting a consistent approach with patients. When conflicts are severe, the clinical team can sometimes exacerbate, through its own chaotic element, the disturbances in the minds of its patients. In this extreme, patients may be pulled into staff conflicts and used to augment one side or another of a particular staff difference. This paper argues that for the clinical team to endeavour to reach its maximum potential, there has to be a reasonable degree of resolution and agreement around three 'constructs' of potential conflict: ideology, power and boundaries.

\section{Ideology}

Psychiatry is a subject characterised by a multiplicity of differing ideologies: the psychodynamic, the behavioural, the cognitive, the medical model etc. In the social sphere, there is the well developed drive to integrate psychiatric patients into the community, now being countered by the continuing need of some patients for 'asylum'. Even within wards claiming similar philosophies, different staff cultures may prevail; one adopting a rigid, autocratic approach to patients, another encouraging patient participation in their treatment, with flexible boundaries over decision processes. While it is true that many clinical teams are, to a degree, eclectic in their ideology and philosophy, for the clinical team to function at its optimum, it has to arrive at some overall consensus about its philosophy and approach to patients. I give two examples of problems which ensued when this was not the case.

A therapeutic community approach was being developed on a ward which has previously functioned as a pre-discharge ward, mainly for psychotic patients. With the new approach, regular community meetings were initiated and patients were encouraged to participate in ward decision-making. Unfortunately, there was a severe staff conflict between those who supported the therapeutic community philosophy and those who wanted the ward to revert to its more traditional role. Problems which occurred on the ward, and whether or not they were successfully resolved, become highlighted as a means by which staff in the opposing camps could provide justification or condemnation for the new approach being attempted. Behaviourally disturbed patients were thus placed in an insecure environment with the opportunity to play one group of staff off against another.

On visiting a female patient of mine on a rehabilitation ward, which was run along fairly autocratic and structured principles, I sat in the day room and talked to her. The patient had no tobacco and borrowed some from a fellow patient. At this point, the staff nurse ran from the office and grabbed the tobacco from her hand, telling her borrowing tobacco was not allowed. As I prefer a more 'social philosophy' with my patients, I gave her one of my cigarettes. The nursing staff were enraged and accused me, with, I admit, some justification, of undermining their ward policy. My emotionally disturbed patient, however, required consistency, not confusion from her carers.

\section{Power}

Over the last 20 years, the power structure of psychiatry has undergone a transformation. The oldfashioned medical directors have almost become extinct. The role of consultant as leader of the clinical team has become open to challenge. In some specialty areas, it has become accepted that the appropriate team leader is not necessarily medical. Whereas once the consultant's overall authority tended to be automatically accepted, power and authority within the team may now be fluid. 
I would assert, however, that for a clinical team to function effectively, a hierarchy has to be accepted by the team members. If a hierarchy is not present, or in disarray, a struggle for power is likely to develop between members of the team, until one is established, much in the same way as we commonly witness in politics. If, on the other hand, a hierarchy develops which is too rigid and autocratic, team members not sufficiently influential in the hierarchy may be unable to function at their optimum and are liable to become increasingly frustrated. As with the 'construct' of ideology, non-resolution of conflicts over power within the clinical team can have a negative effect on patient care and treatment. Again, I give two examples.

A consultant who maintained an autocratic and distanced approach to his clinical team was challenged by the psychologist over an important decision that he had made. The consultant felt his authority under challenge and in order to assert his power in the future over clinical decisions, endeavoured to minimise the psychologist's future contact with his patients. The psychologist left the situation feeling frustrated and angry. The patients of this particular consultant no longer had easy access to psychological services. Ascommunications broke down between the consultant and the psychologist, the problem persevered.

A clinical team meeting was called to decide upon the admission of a patient. Power within the team, as to who had final responsibility for patient admissions had not been clearly established. At the admission conference, the consultant favoured admission of the patient, although all other members of the team argued strongly against this. Against the advice of his colleagues, the consultant decided to admit the patient. He was worried that he might lose his overall influence and power over patient admissions and made a decision to use the patient, in order to demonstrate and confirm his final authority in this area.

\section{Boundaries}

In the same way as ideologies and power hierarchies have to be established, clinical team members have to develop a code of professional boundaries with each other, in respect of their independence and control over their areas of expertise. If boundaries are not adequately developed, so that team members feel it is acceptable practice to repeatedly invade each other's roles and decision-making capacities, then a confusion can develop about who is responsible for what and individual team members are unable to assert control over their own professional areas. Contrarily, if boundaries develop too rigidly, there is a loss of the ability for team members to confront each other construc- tively and learn from other people's perception of their work.

A common example of poorly defined boundaries is the clinical team where lengthy discussions of a problem are easily generated, but decisions are elusive, because respective responsibilities of team members for particular problems have never been adequately delineated or accepted by the group. On the other hand, the team in which it is considered 'taboo' for one profession to comment or make criticism on the work being done with a patient by another profession, is unlikely to serve the best interests of the patient.

A specific example of serious repercussions for a patient in a boundary dispute between nursing staff and the ward consultant is as follows. The ward staff were accustomed to their consultant acting in the capacity of 'team manager' but not relating closely to the patients on the ward. A new consultant arrived and started seeing one of the patients for frequent psychotherapy sessions, which were conducted in a ward side-room. The nursing staff perceived the consultant as acting outside the previously accepted 'consultant boundaries' and felt threatened due to the consultant's increased involvement with the patient and the ward. This they interpreted as their territory being invaded. Resentment and suspicion built up and was projected onto the patient. The underlying issues were not openly discussed. A situation of escalating emotional pressure resulted and the patient was discharged prematurely.

\section{Comment}

Conflicts are bound to occur in clinical teams, whether they be related to ideology, power or boundary disputes. Conflicts are also related to the individual personality, attitudes and values of team members. In some cases a conflict, at one level, over boundaries may hide a second over a power or ideology dispute, or vice versa. The degree of conflict present can vary dramatically from one clinical team to another.

In the examples I have given, patients either became directly involved in conflicts within the clinical team, or were otherwise affected by them. The important question would appear to be how can conflicts be managed so as to minimise any negative or destructive effects on patients. Alternatively, the problem could be stated as to how can the clinical team develop best for the maximum benefit of the patients.

It would appear essential that clinical teams, besides examining and making decisions on their patients, have also to be prepared to look critically at their own methods of functioning. Team qualities necessary for this include good communication, well developed team cohesiveness and an acceptance by 
team members that conflicts will happen, with the acknowledgement that conflicts within the team can be intimately connected with patient care. When significant team conflicts are identified, it is important that the clinical team makes space or takes 'time out' from patient issues to look at their own methods of operation and relationships. In my experience, conflicts successfully worked through increase the team's strength and effectiveness, whereas conflicts which remain unresolved not infrequently persist with a destructive potential. It is hoped that the three 'constructs' I have illustrated in this paper may provide some assistance to clinical teams in examining their performances and internal functioning.

\section{Acknowledgements}

I would like to thank Helen Krydowska and Norman Coates for their help in the preparation of this paper.

\title{
The times
}

\section{False confessions: a note on the McKenzie judgement}

\author{
A. M. P. Kellam, Consultant Forensic Psychiatrist, Whitchurch Hospital, \\ Cardiff CF4 7XB
}

The Court of Appeal in its judgement of this case ruled that special care needs to be taken in cases where the defendant suffers from "a significant degree of mental handicap" (This term is used with a specific legal meaning-see below) if the only evidence against him is his confession.

If there is evidence, which may include the opinion of an expert witness, which shows that the confession is not reliable then the Judge should withdraw the case from the jury and direct an acquittal. The judgement stressed that a confession should not automatically be regarded as reliable because it contains information which should only have been known to the perpetrator of the offence ("special knowledge") but that a careful examination of all possible methods by which the accused may have obtained such information is also essential. Psychiatrists will, of course, be fully aware of the risks of unconsciously transmitting information to persons being questioned and treat with suspicion all information not obtained under "double blind" conditions.

Prior to the decision in McKenzie, the law stated that a case against a defendant must be withdrawn from the jury (and the defendant should be acquitted) if at the conclusion of the prosecution case the evidence against him is such that no reasonable jury, properly directed on the law, could arrive at a guilty verdict based upon it. The judgement in McKenzie's case makes it plain that in certain circumstances a case in which the defendant has confessed to the offences should be treated in this way. The Court ruled that it would not be safe to allow a case to continue where the following three conditions are satisfied:

(a) the prosecution case depends wholly on a confession

(b) the defendant suffers from a significant degree of "mental handicap"

(c) the confession is unconvincing to a point where no jury, properly directed, could convict on the basis of it.

It may be that where the last condition is satisfied it is not necessary to satisfy the other two as it is already the law that a case so unreliable that no jury could convict on it should be withdrawn from the jury. 